\title{
Drying Vehicle Bodies from the Inside
}

\begin{abstract}
A newly developed process allows car bodies to be dried from the inside out. This innovative technology meets all the requirements for the drying processes of the future. The transverse operating mode of the new process, which is in use for the first time, makes it possible to design highly compact systems.
\end{abstract}

The EcoInCure system developed by Dür is a completely new heating concept for automotive finishing. The air flow in the new dryer ensures that the top coat has a highly consistent finish and that the process is extremely reliable. Nozzles with long throw distances are aimed into the inside of the body through the opening for the windscreen and it is heated from the inside out. This guarantees very consistent heating and cooling of the entire body, reduces thermal stresses on the components and cuts the time needed for the bodies to reach the required temperature by up to $30 \%$.

This new method of drying car bodies brings particular advantages for the increasing number of electric vehicles. These are designed with heavily reinforced rocker panels to protect the batteries in the event of a side impact. The new heating method that starts from the inside is particularly effective at drying these rocker panels, which are made from very thick materials. The same applies to the new generation of vehicles that make use of innovative materials, different material combinations and new joining methods. In this area in particular, the reduction in the thermal stresses on components that results from the new drying method also leads to a much more reliable process.

\section{Defining individual heating and cooling processes}

The air flow speeds of the dryer are very low on the outer skin of the vehicle to ensure that the paint finish is consistent.

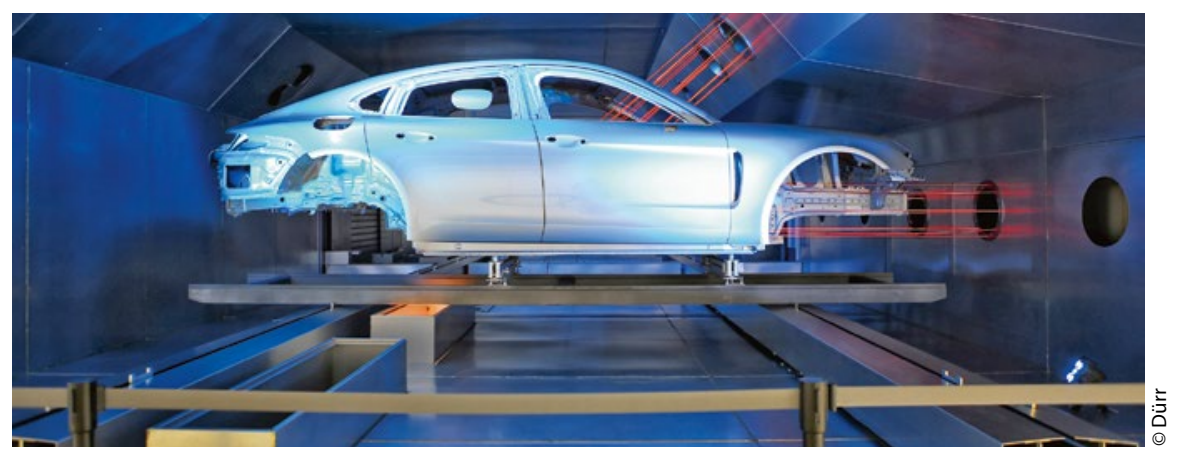

The bodies are heated from the inside out using nozzles with long throw distances.

The air flow in the innovative drying process guarantees the best possible top coat finish.

This significantly improves the appearance and flow of the top coat. A range of different body types can be dried efficiently using the new system, because the temperature and volume flows can be adjusted to suit the requirements of each type. Different heating and cooling processes can be defined for individual bodies. This is made possible by the cyclic operating mode and the option of assigning a separate unit to each module.

Another new feature of the heating system is its central heat exchanger. Instead of having local heat exchangers in the air circulation units, every zone is supplied with centrally heated circulating gas. This type of air circulation system is more flexible and more accurate, reduces pressure losses and lowers the overall energy consumption of the dryer by $25 \%$.

The new design of the system, which has the bodies passing through it transversely, keeps the space required to a minimum. The dryer is half the length of its conventional equivalents. In addition, no steel structure is needed because the air circulation units are located on the same level. The result is that much more efficient use can be made of space in both new paint shops and conversions of existing paint shops, which gives them a more flexible capacity.

Every vehicle body receives an individual software-based quality certificate for the entire drying process. This means that the drying conditions for curing paint and for hardening steel and aluminium for the purposes of crash safety are fully traceable. The data is recorded and evaluated by the iTAC.MES.Suite (formerly EcoEmos) software package. iTAC.MES.Suite is Dürr's new generation of production control systems, which ensures that the drying conditions for the bodies can be continuously tracked online. //

\section{Contact}

Dürr Systems AG, Günter Buzer Marketing Paint and Final Assembly Systems Stuttgart, Germany

Tel. +49 7142 78-2614

guenter.buzer@durr.com

www.durr.com 